DOI https://doi.org/10.30525/978-9934-26-065-0-7

\author{
Nataliia Chuprina, \\ Doctor of Study of Art, Professor, \\ Professor of Department of Artistic Designing of Costume, \\ Kyiv National University of Technologies and Design, \\ Kyiv, Ukraine \\ ODCID ID 0000-0002-5209-3400 \\ Olena Kolosnichenko, \\ Doctor of Study of Art, Professor, \\ Professor of Department of Artistic Designing of Costume, \\ Kyiv National University of Technologies and Design, \\ Kyiv, Ukraine \\ ORCID 0000-0001-5665-0131
}

\title{
POP ART IMAGE AND DESIGN CHARACTERISTICS AND MODERN DESIGN TRENDS ASSIMILATION
}

\begin{abstract}
The purpose of the paper is to study the artistic style of pop art, to identify the problems of research in the context of modern fashion design. The article considers the means of graphic expressiveness in the work of the main representatives of pop art, the evolution of compositional means and techniques, the features of the color scheme and original texture as a way to influence society through the design and implementation of fashionable clothing.

The methodology of the study is based on the principles of a systematic approach to the formation of the clothing range, methods of historical and logical development, comparative, system-structural and morphological analysis, which made it possible to study the costume in the process of development and identify the characteristic features of the artistic style of Pop Art in the design concepts of designers at the beginning of the third millennium.

The scientific novelty consists in generalizing and systematizing experience in the practice of fashion design in order to predict the development of forms of author's collections based on artistic and compositional principles and methods of stylistic transformation.
\end{abstract}


Nataliia Chuprina, Olena Kolosnichenko. Pop art image and design characteristics...

The conclusions. The paper comprehensively examines the artistic style of Pop Art: based on the analysis of artists ' creativity, the main techniques in the variety of decorating modern fashionable clothes, the use of graphic lines in shape and silhouette, geometric cut, bright colors are revealed. Variable possibilities of improving the design of modern clothing collections by adapting the prototype and design properties of pop art are presented.

Keywords: contemporary art, fashion design, pop art style, clothing shaping, modern fashion.

\section{INTRODUCTION}

Contemporary art is driven by the growing role of culture and art in postmodern society, as the most important mechanisms of human self-development and self-knowledge. It seeks to provoke the intellectual participation of the viewer, to stir the mind and demonstrate a radically new experience of understanding the world; it opens new horizons and generates a desire to study and discover it. The problems of contemporary art are considered through a review of scientific and historical literature.

Today, we are amazed by the many fashion elements, style solutions, conceptual ideas and a number of principles for an objectively successful result in terms of creating and implementing a fashion designer closing brand, trade name and their subsequent release. One cannot really argue that the Ukrainian fashion industry today is conceptually new or impressive, its demand is growing at a fairly moderate pace. Conceptually, the first step to the success of the Ukrainian fashion industry was the launch of Ukrainian Fashion Week in 1997, the Fashion Week, which was recognized as the first professional Ukrainian fashion event. And despite the fact that many promising fashion brands have appeared today, the operation of Ukrainian Chamber of Fashion, the holding of numerous festivals and art exhibitions, the publishing of fashion magazines, however the infrastructure of the modern Ukrainian fashion industry does not fully ensure the development of this industry. Fashion in Ukraine has just begun to develop, so there are some difficulties in developing own algorithms for brand development. However, the emergence of new talented designers and remarkable brands, creative photographers and stylists, successful advertisers, marketers and other professionals in the fashion industry contributes to the growth of the future of the Ukrainian fashion industry and its entry into the world market. 
The designer rethinks and conveys to the viewer their understanding of reality, resulting in new ideas of costume forms and images. The associative thinking of the artist is the basis of a creative approach to clothing design. Since the creative process of a clothing designer is an achievement of unity of form and content, the basis of creativity in the artistic design of a costume is the image-associative approach to the creation of clothing.

Creating a holistic artistic image of a person and a costume is the main task of a fashion designer in modern society. The priority of a person when creating a costume is due to ergonomic, functional, psychological and other requirements. A costume combines aesthetic and practical qualities, so the creation of an expressive costume image involves the task of meeting all the requirements that apply to it.

The way to transform the creative source into a certain form of costume is a series of successive stages, step by step, guiding the artist to achieve their goal. The result of a properly organized process of artistic design, or costume design, is a product of design, i.e. a product progressively solved from the standpoint of technology, economics and aesthetics. The design and requirements of society are directly related, because society gives a social order for the production of products of a certain nature and level.

The universality of this method of artistic design of the form and aesthetic properties of a costume will give a tangible effect for the preparation of production and the consistent introduction of author's models in production in the development of promising clothing collections. The use of this well-known approach and well-known motives, will be quite relevant today, because, despite the changing times and cyclical fashion, a person remains the most interesting and desirable object of discussion for the "sharks" of this pragmatic world. In this way, it is possible to quite interestingly, but openly and kindly, show people and society as a whole what world we live in and what surrounds us.

\section{POP ART AS AN ART OF MASS CULTURE}

In the modern world of art, one can often hear the concept of "pop art", the meaning of which few people think about. At the same time, its meaning and significance has changed to date. Pop art is perceived as something poorly done, of low-quality. However, pop art is an art that is aimed at the masses and at the same 
Nataliia Chuprina, Olena Kolosnichenko. Pop art image and design characteristics...

time well-done for everyone. Pop art has had a huge impact on the development of modern art, its traditions are preserved today. It eliminated the boundaries between art and life, proved that the thing exhibited in the museum will be perceived by the audience subconsciously differently. A person involuntarily begins to treat an object from everyday life differently, it opens the desire to think and understand the idea of the opposition presented.

Pop art appeared at a time when it was necessary to show society the unusualness of thinking, to move away from traditions, canons, classicism. The media and advertising are the main topics of pop art. It is available to a wide range of consumers. Television, comics, posters are all clear and familiar to a fairly wide target audience. A person belonging to the mass society of the second half of the twentieth century became one who was seeking to acquire, to own both necessary and unnecessary things. Sociologists characterize such an industrial society as a society of mass consumption [28].

The period of the 1950s-1960s was marked by increased interest in the so-called mass culture, that was also the time when pop art appeared. It is safe to say that many ways of expressiveness of pop art are found today in various graphic projects, advertising posters, billboards and even in interior design and costume. Quite often it is possible to meet people on the street in clothes using prints in the style of pop art.

Pop art is a trend that developed first in modernist visual art, and then in various spheres of mass culture of the twentieth century. Pop art originated in the United States and Great Britain and finally established its foothold at an international exhibition in Venice (1964), defeating abstractionism.

Pop art returned an object to art, but it was an object not poeticized by artistic vision, but rather a deliberately household object, associated with modern industrial culture and, especially, with modern forms of information: printing, television, cinema. New techniques borrowed from industrial design and advertising: photo printing, the use of a slide projector, the inclusion of real objects, contributed to the "depersonalization" of the individual creative style of the artist, and "disclosure of aesthetic value" of mass production samples. Pop art became one of the most common trends in Anglo-American art in the mid-twentieth century, which influenced the art of other countries. It is one of the first large-scale manifestations of post-culture and one of the most striking 
phenomena of modernism. And many artistic practices of the second half of the twentieth century relied, one way or another, modifying its basic elements and techniques, on it.

By removing elements of the image of mass culture from the everyday environment, moving them into the context of the created artistic space, pop artists built their works on the basis of playing with the meanings of mass stereotypes (new contextual connections, different scale, colour, sometimes deformation) in a new semiotic environment. Early works of pop art were performed in collage techniques or traditional painting with elements of collage (Fig. 1). Later, the materials used and the technique of creating pop works significantly expanded and complicated. Foreign elements were actively introduced into traditional painting, for instance, fragments of plaster images, objects of everyday reality, photographs, details of machines.

There were pop sculptures, objects, assemblies, installations, which used a variety of materials, including a large number of things that were in use, i.e. the contents of rubbish cans and dumps. Compositions were often created from packaging cardboard, containers of consumer goods and similar materials. Pop art artists are not limited to static works. They create pop art actions - happenings, environments, etc. The latter are especially characteristic of the representatives of American pop art [2].

Representatives of pop art offered the viewer art that operates with familiar objects, which, being torn from traditional connections with the surrounding objects, appeared in random, paradoxical combinations. Pop art has its own ideas, techniques, representatives, characteristics and features that distinguish it from other types. Today it is relevant, in demand. That is why today it is found in architecture, painting, interiors, etc. [27].

The attention of pop artists was attracted by the surrounding world of mass culture, designed for mass consumption, a world in which aesthetic and spiritual values were equated with consumer, everyday, social, and vice versa. Reality seemed to have been demythologized, the masters sought to present a kind of encyclopaedia of modern life, focused on the "great American dream." Artists used the motives of the profane, that is, everyday, public, banal and anonymous in life, something that can be easily recognized. Television, advertising, comics, radio, pictures from magazines, the usual images of the media became the object 
Nataliia Chuprina, Olena Kolosnichenko. Pop art image and design characteristics...

of image in pop art and began to be equated with such symbols of beauty as the Mona Lisa or Venus de Milo (Fig. 2).

Mass information, standardization of consumer goods, manufacturability are the real basis of pop art. Demonstrating great flexibility and mobility in understanding what can turn out to be art, "expanding the artistic situation", pop artists destroy the hierarchy of images and plots, materials and forms. In this system of values, Leonardo da Vinci and Mickey Mouse, painting and technology, hokey-pokey and art, kitsch and humour can be on the same level. It is known [26] that the word "pop" first appeared on one of the collages of Eduardo Paolozzi in 1947, and in 1954, Lawrence Alloway, an English art critic and writer drew attention to the definition of "pop" in one of the paintings of the artist R. B. Kitaj and began to use it in his articles. In 1956, the word "pop" appeared in Richard Hamilton's famous collage, "Just what is it that makes today's homes so different, so appealing?" (Fig. 3).

Pop art flourished in the 1960s. Many saw it as the antithesis of abstractionism, and many critics saw pop art as "non-art". There was some truth in this, because pop art did not seek to be an art in the traditional sense. It sought a middle ground between art and life, or rather, tried to combine art and life. Klaus Oldenburg said that pop art is an art that does not know that it is art. Pop art was characterized by a call to "expand the situation of art", to expand the concept of art. Everything can be considered as art, it is enough to call this or that fact or object "art." The word

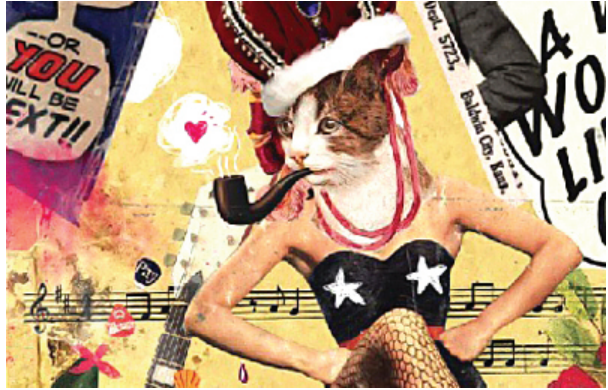

Fig. 1. R. Hamilton "Just what is it that makes today's homes so different, so appealing?"

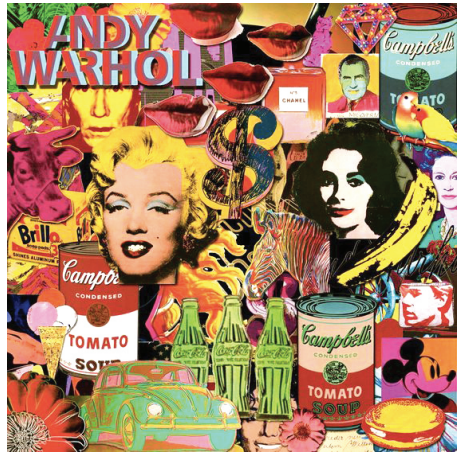

Fig. 2. Pop art images 
"art" could appear on any object and define it as an artefact. After all, pop art is right when it comes to the real "artificiality" of human culture compared to nature. It is no coincidence that one of the theorists of pop art proposed to treat the whole of human society at a certain time intersection as a work of art [16].

Often, pop art is seen as a purely American phenomenon that reproduces a certain (namely, American) lifestyle. However, in parallel with the American version of pop art (and some researchers claim that even earlier), the concept of this avant-garde trend was developed in England. In 1952, a group of artists called "Independents" was formed in London. The members explored the artistic and aesthetic possibilities of advertising materials. Among its participants were Eduardo Paolozzi, Peter Blake, and Lawrence Alloway.

English artists were interested in the design of American illustrated magazines, paying special attention to the technique of advertising photos, seriation of images, visual and semantic contrasts (Fig. 4). Artists have come to the conclusion that in advertising not the whole object is reproduced, but only its certain quality, that forms are not invented (they already exist), but only add up to original blocks of a video sequence. In this way, standard visual images are formed, which carry certain predicted information and evoke certain

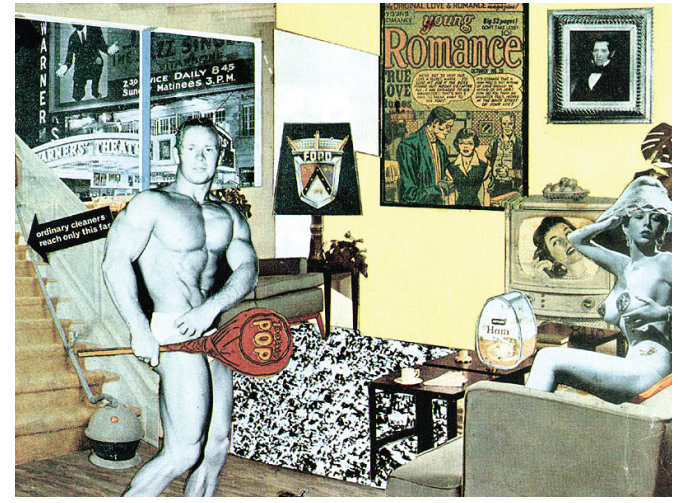

Fig. 3. R. Hamilton "Just what is it that makes today's homes so different, so appealing?"

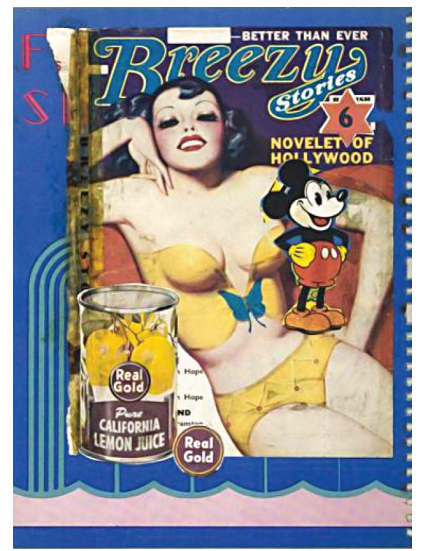

Fig. 4. E. Paolozzi

"Real Gold" 
Nataliia Chuprina, Olena Kolosnichenko. Pop art image and design characteristics...

pre-predicted associations and emotions. A significant role is played by the pleasure of "recognition" of something familiar in a stranger (which will later be used in a slightly different way by post-modernism). However, in England, as, after all, in other European countries and Japan, pop art has always remained a somewhat exotic avant-garde phenomenon and has not become as widespread as in the United States.

In 1964, one of the most famous masters of American pop art, Robert Rauschenberg, won the Grand Prix at the Venice Biennale (a traditional world exhibition of contemporary art held in Venice every two years. In 2001 at the 49th Venice Biennale Ukraine was represented for the first time.) $[8,14,18]$.

Among the first program works for pop art, which gained textbook popularity, were collages by E. Paolozzi “I Was a Rich Man's Plaything” (1947, London, Tate Gallery) (Fig. 5) and by R. Hamilton "Just what is it that makes today's homes so different, so appealing?” (1956, Tübingen, Kunsthalle). Image elements are clippings from brochures and popular magazines. Both the works contain a motto of this genre - the word "POP."

In terms of content, material, manner of execution and type of artefacts,

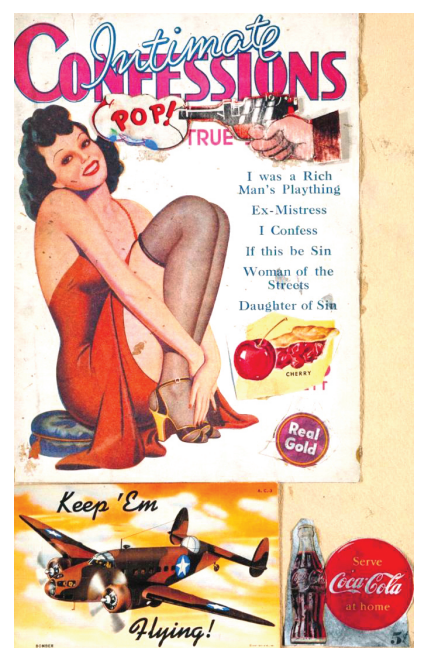

Fig. 5. E. Paolozzi "I Was a Rich Man's Plaything” pop artists are very different from each other and thus once again indirectly demonstrate their deep belonging to the colourful, albeit standardized everyday life of mass society. For example, D. Jones often uses means of painting, close to abstract expressionism. However, he became popular due to nearly illusionistic, naturalistic images of the American flag in various variants and scales and target shapes.

T. Wesselmann is characterized by poeticization of idealized-advertising eroticism of the female body. His compositions usually consist of a planar, simplified silhouette image of naked female figures in combination with some specificobject fragments of the interior. Many of his other works were performed in a similar 
manner. R. Lichtenstein made semi-mechanical paintings on canvas resembling magazine comics, and increased them in scale. C. Oldenburg created objects and installations from a variety of materials. Here is a combination of real objects with painted plaster models (usually perishable food - pieces of meat, vegetables, bread); and anthropomorphic compositions of figures cut from packaging cardboard; and installations of a variety of objects, partially painted with oil; as well as a series of soft inflatable household items: toilet, typewriter, phone, vacuum cleaner, etc.; and, finally, whole interiors of rooms, reproduced in full size from real things in the museum space (for example, the "Bedroom" at the Museum of Modern Art in Frankfurt and similar interiors in other museums around the world) [4, 12, 23$]$.

A. Warhol created silk-screen series based on photographs of Marilyn Monroe, individual fragments of her face (lips, eyes), dollar bills, bottles of cola, etc. (Fig. 6). R. Rauschenberg combined painting techniques with the creation of objects and installations from a variety of materials (usually short-lived, everyday), the so-called "combined painting."
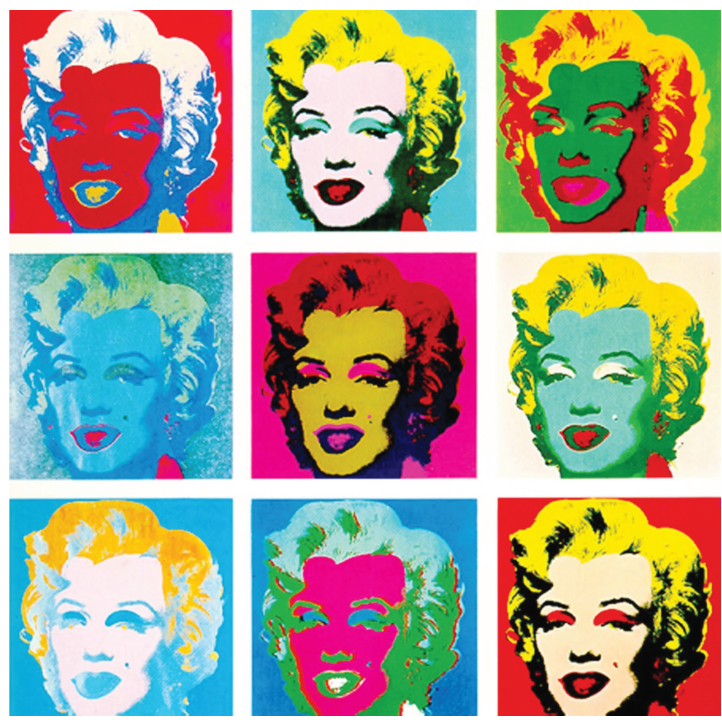

Fig. 6. A. Warhol "Marilyn Monroe" 
Nataliia Chuprina, Olena Kolosnichenko. Pop art image and design characteristics...

J. Dine hangs lightly painted carpentry tools on the upper edge of the empty canvas. J. Rosenquist painted with bright, often poisonous and cutting eyes colours synthetic paints huge multi-meter compositions, composed of illusory elements, fragments, symbols of scientific and technological progress of the twentieth century.

G. Seagal created, as a rule, spatial groups of white plaster figures of people in life-size [17, 20].

Some of Seagal's works, and especially E. Kienholtz's compositions, assemblies, and installations with anthropomorphic figures collected from the wreckage and details of technical devices and machines, have a terrifyingly absurd-surreal character. They show with special force the absurdity of the "ideal" everyday life of modern mass society, which is idealized by the American state machine and romanticized by some early pop artists; in some of them, the internal existential devastation of a man of this society is expressed with expressive piercing [11].

In general, pop art actually drew a line under traditional forms of fine art, bringing them to a logical conclusion, and paved the way for fundamentally new types of artistic practices that explore a variety of spaces through many visually perceived forms, objects and methods of non-utilitarian activity of modern art.

In particular, pop art has prepared the ground for conceptualism and post-modernism.

\section{POP ART ARTISTIC IDEAS}

\section{AND WAYS TO IMPLEMENT THEM IN DESIGN}

In modern civilization, the development of the environment is not so much through sensory experience, as through its fiction, surrogate, and substitution grows from the fact that our perception of the world of things is determined by technical means of reproduction, replication and interpretation (photo, TV and video, various types of printing, including circular printed graphics, for example, in the form of silk-screen printing), which are used by modern media, both digital and "paper." This is the move offered by one of the most influential genres of art of the second half of the twentieth century — pop art [13].

The idea to eliminate the personal beginning in a work of art, to turn this work into an impersonal object, almost into a mass industrial product, has occupied the minds of a number of artists since the very beginning of the twentieth century. 
On the way to discovering creative individuality, the avant-garde trends of the beginning of the century - expressionism, but even more cubism and various types of abstract painting - nearly reached the maximum.

Pop artists like to use a technique started by Dadaists: placing objects in an unexpected and inappropriate place, environment, and so on. The object is thus isolated from the usual context, and acquires the character of a sign-symbol associated with the urban environment, the latest technology, the realities of modern life. And, of course, acquires an unexpected sacredness [15].

As a creative tool of pop art, the following example is common: a refrigerator installed on a safe in the warehouse, and the same combination in the exhibition hall are perceived by the audience in completely different ways. In the latter case, the factor of "museumification" is triggered in the mind - a different attitude due to the involuntary desire to understand what you are offered to see. In theory, everyday objects should evoke a different, more attentive attitude to them of the viewer, if they are in a special space. Another "magic" technique was used for the same purpose: any image was repeated an infinite number of times. For example, Warhol "replicated" images of a Cola bottle, the face of actress Marilyn Monroe on huge billboards resembling advertising. The magic of such works is that any object that has attracted the artist's attention, becomes in this approach mundane, accessible to consumption (in this case, intellectual and emotional). On the other hand, such a "serial approach" reflects the desire of the mass consciousness to create idols.

Pop art is different in style. For example, T. Wesselmann (born 1931) used solid, even spots of colour, and Roy Lichtenstein (born 1928) likened his paintings to newspaper printing, carefully reproducing raster grains. However, all works are characterized by a large scale, clear, bright picture. And in any transformation, the viewer is not presented with a work of pop art (whether a painting, a cast of the human body or a "finished object"). In the work, one can always read the program idea - expanding the concept of art beyond the actual artistic activity [7].

So, one of the ideas of pop art is a game of contrast, the lack of rigid frameworks and canons. Impersonal objects of mass culture with fresh flowers are bright, unusual and temporary: "Used today - thrown away tomorrow." "Pop" means to be modern and fashionable, so in our works we use the most popular items of the twenty's century, which delight us every day. 
Nataliia Chuprina, Olena Kolosnichenko. Pop art image and design characteristics...

Many pop art creators use creative methods that came from Dadaist experiments, when the form is not modelled from material, but composed of artificial objects. Thus, the assembly has become a springboard for multifaceted thinking, which is becoming increasingly important for the artist - for the art of the environment and happening. It also leads to new forms of creativity: combination of spatial objects, which can include the viewer in the installation. Pop art also had an impact on the art environment without happenings. Artists experimented with real objects.

Pop art is a style of art that has been sharply criticized, as it deviated from accepted rules, intertwined with the work of advertising, artists sometimes depicted girls who attracted attention to themselves and not to the product, which certainly the average society could not like.

On the one hand, we can say that pop art is the art of the masses, so it is difficult to perceive it as masterpieces of art, on the other hand, some paintings and sculptures have become unique, they are admired.

Thus, it is difficult to talk about pop art as a genre of art, because it is contradictory, contains many facets, it always opens up in a new way.

The modern pop art carries a new vision of the world, art in general. In the idea and in the works of pop art, the new expression of the world-view aims not so much to affect vision as to form a thought. This art represents the modern world, contemporary artists and their uniqueness. Each person, looking at works in the style of pop art, understands them in their own way. For the still unformed personality, such works can play a very important role in the further development and world-view.

In contrast to Dadaism, pop art was established at another time, when the media became one of the most important factors influencing culture and art. The information became available to everyone. And art remained the treasure of only selected connoisseurs. Pop art felt the need for new, open art well. It used recognizable concepts and objects [19].

\section{CONCEPTUAL PRINCIPLES OF ANDY WARHOL'S WORK AS A BASIS FOR THE POP ART FORMATION}

Andy (Andrew) Warhol (1928-1987) is traditionally considered a leading artist (or even a founding artist) of pop art. 
Making a name for himself in New York, Warhol at the same time learned about the cultural life of the metropolitan city. He led a rich and active lifestyle: visited libraries, ballet and opera performances, galleries, museums, and this experience was later transformed in his work.

In 1956, Andy Warhol left the United States for the first time on a long journey around the world. He visited Japan, Cambodia, India, Egypt and Italy. In the end, the artist came to the conclusion that his artistic ambitions go beyond purely commercial art. For the first time after years of study, Warhol returned to easel painting, made friends in the artistic environment of central Manhattan, and became interested in avant-garde forms of the arts new for himself, including dance, theatre, and cinema [3].

Creating paintings "Coca-Cola" (1960), “Telephone" (1960) and "Campbell's Soup Cans" (1960-1962), the artist starts from the images found in newspaper and magazine advertisements, comics and other products of mass culture. In 1962, Warhol used the technique of silkscreen reproduction to transfer the image directly to the canvas, using advertising stencils, frames from films and photographs as objects. His portraits of Elvis Presley, Elizabeth Taylor and Marilyn Monroe have become real symbols of American pop art.

Over the years, Warhol's magazine topics have expanded to include many aspects of popular culture, such as fashion, art, music, television, gossip, and celebrity night-life.

The early 1980s were marked for Andy Warhol by a series of related works in which he used images of rifles, knives, crosses and dollar signs. These series, which consisted of large and small paintings, went beyond the artistic study of popular images, focusing on the symbolism of objects and signs. It is believed that their powerful imagery evokes associations with the insanity and godlessness inherent in certain aspects of modern Western culture.

At all stages of his forty-year career, Warhol, transforming from a commercial illustrator-advertiser to a radical innovator, from a novice cinematographer to a master of portrait painting, from a humble observer to an international star, played a leading role in establishing artists as major figures in American life. Warhol's legacy goes far beyond his many and varied paintings. He left behind the freedom of creativity that he allowed himself and to which he encouraged others, and the attitude to art as a serious work, a business, which was established through 
Nataliia Chuprina, Olena Kolosnichenko. Pop art image and design characteristics...

his success. Demonstrating the importance of being an artist in everything, he also vividly revealed the role of the artist in society. Warhol raised the authority of the artist in society and forced it to respect the artist and their work. Joining film and video, the world of fashion, dance, music and publishing, he proved the practical limitless possibilities of the creative process. Warhol developed the discipline, ingenuity and variety of technical means of creative activity as a commercial artist, graphic designer and illustrator [22].

Andy Warhol turned the art world upside down with his colourful minimalist paintings in the style of pop art. This style was so popular with European bohemians that it is still used - they make reproductions of paintings, draw comics and, of course, return it to modern fashion. Pop art-style clothes look like they came from comics, and everyone who wears them is a colourful cartoon character.

\section{ADAPTATION OF FIGURATIVE AND ARTISTIC PROPERTIES OF POP ART IN MODERN FASHION DESIGN}

It is known that fashion is changeable and capricious, and therefore it periodically offers us an exciting game with time. Every season, something perceived as new comes to us, but in fact it turns out to be a well-forgotten old. And then it's time for a tricky move: to interweave trends of other epochs in a fashionable modern image.

It is impossible to invent something radically new, at least because people have been inventing this new thing for the last six thousand years - ever since fabric existed.

Creating a costume and s holistic artistic image in general is the main task of a fashion designer in modern society. The search for new forms, new options for the selection of textures, environmental and functional solutions, rational design and sophisticated technology - these are the tasks faced by a modern designer. Perhaps the most important factor for the formation of a person's appearance and expression of their internal content is a costume. Clothing is an essential item in a person's life, it belongs to the things of their personal use. Therefore, a fashion designer builds a product model from individual elements. Clothing is very closely related to a person's lifestyle and activity, so it must fully meet their needs and expectations. Fashion is constantly changing, the definition and purpose of the costume is changing $[1,9,21,25]$. 
Designers around the world dictate fashion, every year, every season, every day. Each epoch differs in the expressive means in a costume, in the decision of its composition. When working on creating a costume, it is necessary to select artistic signs of the times that will help to see and feel a special atmosphere. The process of creating a costume is a continuous work, the search for something new and relevant and the accurate use of what is already well known. The inspiration for this search is inspiration and its source. The source of inspiration is a natural or material-cultural phenomenon. When creating a costume, anything can be the creative source: nature and natural phenomena, elements of the environment, engineering structures, household items, individuals, historical periods, elements of anything, appeal to ethnic and historical motifs, objects of decorative arts, historical, national and classical costumes, various textures: soils, frosty patterns on the window, the starry sky, the method of using a certain cut and decorative elements, the method of stylization and much more. That is, everything that the human imagination and fantasy can project on a costume, everything that makes a designer get an idea and is a source of inspiration.

The creative process of creating a costume requires a preliminary analysis of the source of creativity, its integral ensemble and individual components. It is necessary to determine the main and essential in the ensemble and to reject the secondary and insignificant. The transformation of the source of creativity into modern forms begins with the collection of material, its study and research. In the process of research, the designer uses various techniques. This helps to consider the source entirely $[10,24]$.

Under the influence of the surrounding reality, the designer has an idea that is embodied in the artistic image specifically or generally. The image of the idea is transformed into a form that must correspond to the idea. As a result, something is selected that most clearly corresponds to the idea and fashion trends. The participation of the source of inspiration is hardly guessed in the final idea. Various methods and techniques of research and transformation of a source of inspiration are used, which is why it is possible to reach associative impressions and emotions of the art-figurative decision of a costume.

Analysis of many areas of modern fashion shows how shocking, provocative and bright it becomes. Youth fashion of the twenty-first century expresses, first of 
Nataliia Chuprina, Olena Kolosnichenko. Pop art image and design characteristics...

all, not only their beliefs and desire to break out of the greyness of life, but also the inner state - their thoughts, feelings, sensations $[5,6]$.

In the course of the work the fashion tendencies of women's and men's casual clothes were studied, and certain characteristic features of the assortment of dresses, trousers and outerwear, the most common types of cuts, silhouettes, materials were deduced.

The analysis of current modern fashion trends was carried out on the basis of works of world-famous designers of recent years: Moschino, Celine, Prada, Chanel, Tom Ford, London, Paris fashion weeks and others, as well as fan blogs and worldwide fashion reviews. They are the most accurate in depicting and using pop art.

Common features of all selected for analysis of works were:

- the use of materials that best convey the mood and spirit of pop art, i.e. reminiscent of artificial and inexpensive materials (organza, satin, various types of cotton, knitwear, cloak fabrics);

- use of various materials as a décor: prints, embroidery, plastic elements;

- bright colours and saturation of colour scales on a monochrome background;

- the variety of forms, at the same time, brought to a common idea, multiple layers.

Modern youth wants to have a so-called functional look, i.e. maximum comfort, minimum time, but look stylish and bright. That is why, developing this collection, we took into account the holistic image of a girl, which was based on an open face, with healthy skin, minimal make-up, but with an emphasis on the lips, because it is an integral trend of the season, and in the block festive and everyday, also designed for attending art events, bright but light-toned make-up and dyed hair in shades of pink and purple; and also a guy who has a stylish haircut, but it should be comfortable in styling without the need for additional tools, while the hair can be dyed, because, this hairdressing technique is quite fashionable among males.

An essential rule among stylish young people is a complete change of the traditional wardrobe, i.e. bold and decisive clothes. Layering is trendy now. Young people set their own fashion trends, they do not need any advice or direction. Everything that is comfortable, bright, beautiful, creative is for modern youth. 
This proves that the problem is inexhaustible. Inspired by the works of twentieth-century "pop artists", modern designers create stunning collections meaningful and filled with social problems, but at the same time not devoid of individuality and attractiveness.

When working with visual materials, it is apt to apply the subject-analytical method. Using this method, an analysis of the works of the pop artists, E. Paolozzi and A. Warhol on informative grounds, by highlighting and systematizing the pictorial figurative, ornamental and symbolic elements, was carried out. The combination of different media is an integral part of pop art.

The works of pop art artists have a fairly large text link or image of household items, current products, as well as stars of the political world and show business. Interesting are the choices and combinations of everyday life elements in the graphics of R. Hamilton, in the work "Just what is it that makes today's homes so different, so appealing?" and E. Paolozzi "I Was a Rich Man's Plaything”(Fig. 7-8). To determine the colour scheme of the collection, colour spots in the work of A. Warhol "Truck" were analysed. They were used in determining the colour combinations for each of the blocks of the collection (Fig. 9).

The creation of each collection has its own specifics, but there are general patterns of formation of collections, as well as general requirements for them.

The very meaning of pop art is the presence of a large number of decorative. Pop art is in itself decorative, artificial art, so the collection has a large number of clothes decorations. After researching the original source and analysing the techniques and images used by pop artists, the collection used a variety of decorating methods. First of all, decorating began with the choice of bright, and most importantly artificially created materials (organza), which is one of the main conditions of this style. Also, the collection includes prints depicting modern celebrities and imitation materials that are applied by thermal transfer to the fabric. Besides, in the development of the collection, brightly coloured feathers are used, which creates the effect of high cost at the lowest possible cost. This idea was the basis of the works created by pop artists.

The modern pop art carries a new vision of the world, art in general. In the idea and in the works of pop art, the new expression of the world-view aims not so much to affect vision as to form a thought. This art represents the modern world, contemporary artists and their uniqueness. Each person, looking at works 


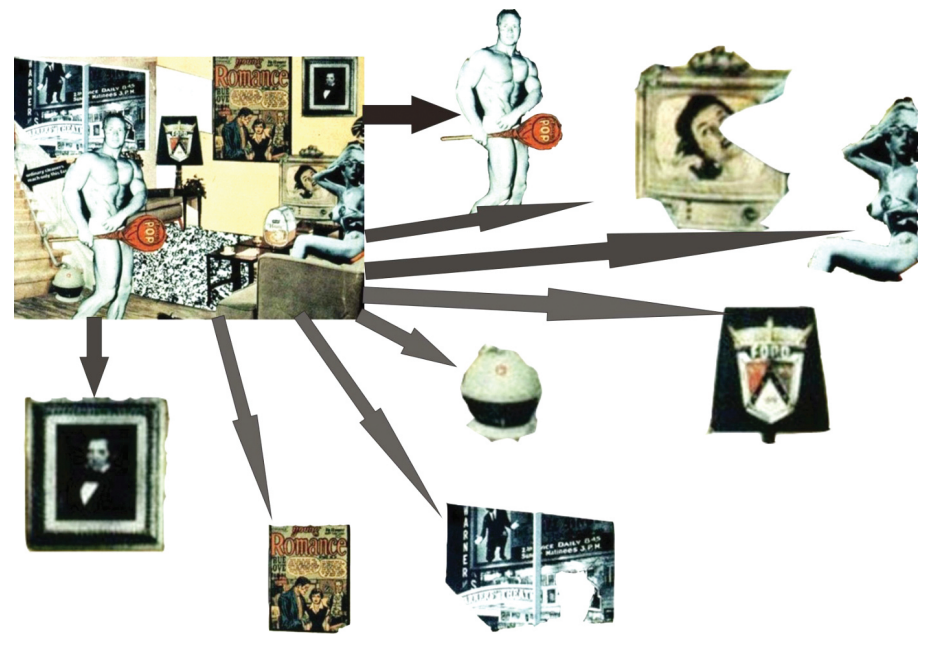

Fig. 7. Analysis of R. Hamilton's work "Just what is it that makes today's homes so different, so appealing?"

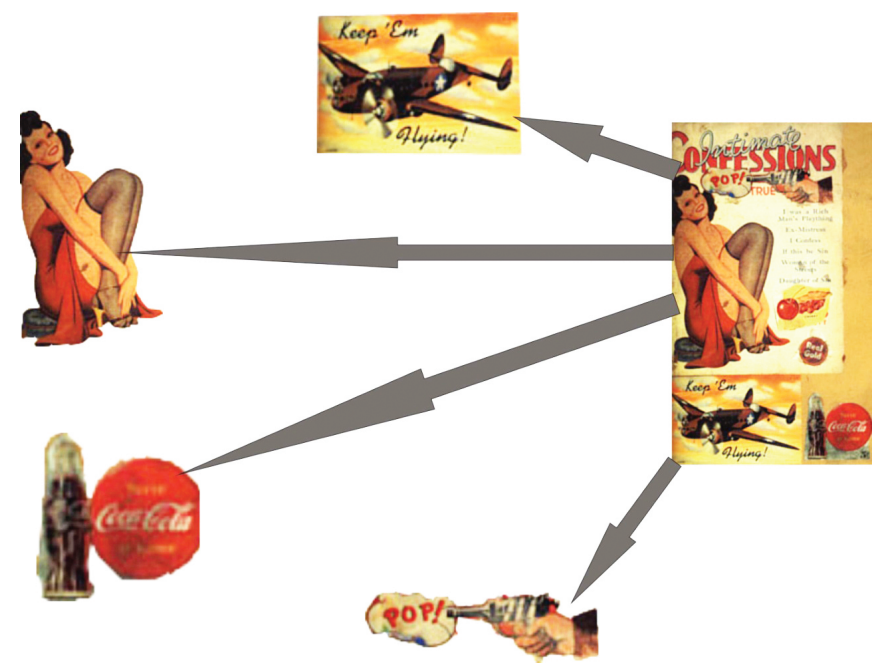

Fig. 8. Analysis of E. Paolozzi's work "I Was a Rich Man's Plaything" 


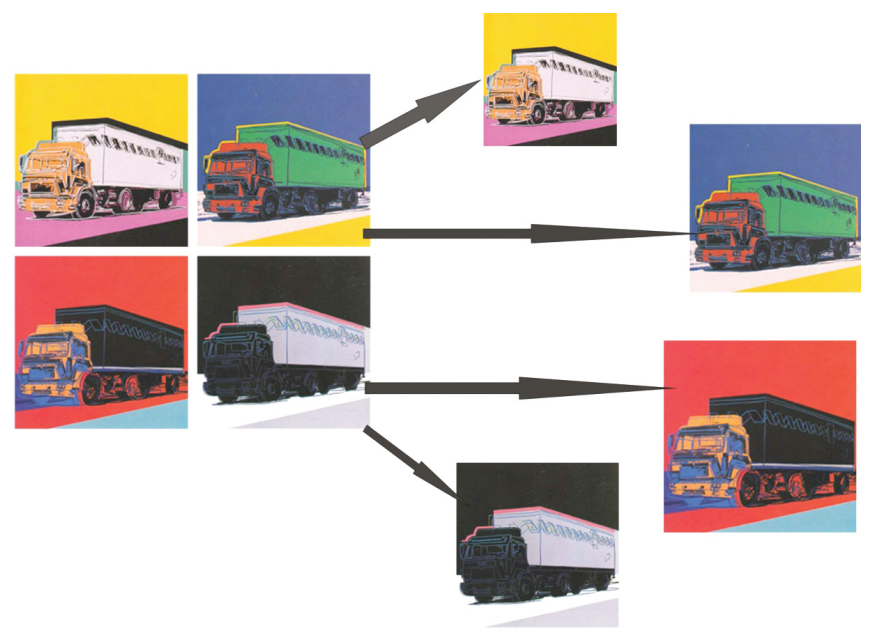

Fig. 9. Analysis of A. Warhol's work "Truck”

in the style of pop art, understands them in their own way. For the still unformed personality, such works can play a very important role in the further development and world-view. The results of the research were used in the development of a modern collection of men's and women's clothing. The principles of collection development can be implemented in mass production, applied in everyday life and in the development of individual consumer image.

A systematic approach to building a collection of clothing models, regardless of the type of collection is a certain sequence of its creation, the general principle of combining models into a collection, i.e. a conceptual approach to its organization, which is expressed in harmonious integrity of the collection, a single design solution in all forms, in accentuation of constructive belts, the uniform colour decision, in use of uniform structures of materials, their combinations and furnishings of products of a collection.

Exploring the theme of "pop art" of the twentieth century and its modern interpretation, one can bring a touch of individuality to a long-familiar plot. In the course of pre-design work, as a rule, the most effective method is the systemstructural analysis - a method of studying the system, which begins with the 
Nataliia Chuprina, Olena Kolosnichenko. Pop art image and design characteristics...

most general description, followed by detailed presentation of certain aspects of behaviour and functioning.

This method allows to accurately determine the main aspects of the formation of the costume, its proportions and internal structure. When reviewing the results of system-structural analysis, it was found that the main signs-symbols are represented in the form of a rectangle, trapezoid and triangle. Having divided the costume into geometric shapes and constituent elements, it is possible to analyse and single out the geometric shapes that will be used when modelling one's own collection [21].

A men's look from the autumn - winter 2015-16 Moschino collection and two women's looks from the spring - summer 2016-17 collection were selected for analysis. The spring - summer Moschino collection is filled with bright orange, turquoise, yellow, pink, blue, glossy black and many other tones. These looks successfully demonstrate retro costumes of juicy shades with a bright print, as well as outrageous models, shiny raincoats and colourful costumes. The male look from the autumn - winter collection perfectly conveys the desired mood, colour saturation on a metallic background, simplicity of cut and a certain fatness of the silhouette. The costume in the style of pop art, which was used during the system-structural analysis, is symmetrical and quite dynamic. After conducting a system-structural analysis of selected images, highlighting the silhouette shape, the most important elements of articulation, dynamics and length of products, the results were summarized in a general schematic sketch, which well traces all aspects of the study.

The morphological method of analysis was used to select possible solutions of individual parts and the subsequent systematic receipt of their combinations. Using this method, one can get many variations in the ratios of lengths, cuts and shapes $[10,24]$.

Morphological analysis is used to select individual elements of the shape of the costume. Then they are systematized and combined, as a result you can get many combinations. Due to this method, one can determine all the design and decorative features of the shape of the designed product. This becomes the basis for building a collection.

After analysing the types of cut and decoration of clothing, fasteners, neck shapes, armholes, a variety of lengths, data were obtained for the formation of matrices of morphological tables. 
After analysing modern fashionable clothes, among which there are such special features as graphic lines, geometric cut, bright colours, a variety of decorations, a number of sketches were developed, one of which was selected and executed in the material. In the course of the work, the current tendencies and directions of modern fashion were investigated on the basis of the materials received from the analysis of works of world-famous designers, fashion blogs and fashion reviews. As a result, a collection of modern casual clothing was created, for various purposes, using as a primary source of graphic works by Andy Warhol (Fig. 10).

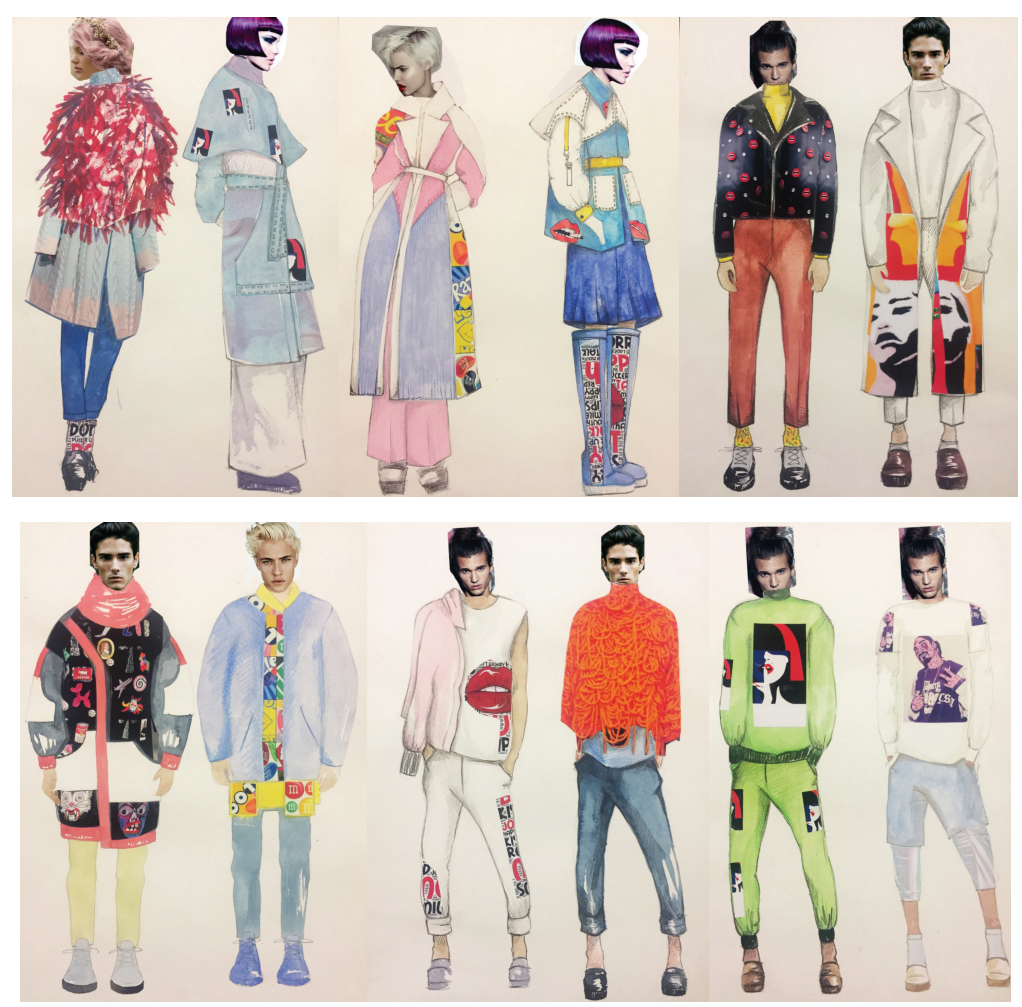

Fig. 10. Models of actual fashionable clothes for youth on the basis of adaptation of prototype-design properties of pop art 
Nataliia Chuprina, Olena Kolosnichenko. Pop art image and design characteristics...

The collection uses motifs of modern pop art: bright prints of celebrities, newspaper motifs, prints of textures. The colour scheme is chosen so as to fully convey the fullness of pop art. Clothes are created in such a way that every fan of this genre of art can afford to buy clothes that would allow one to express oneself, one's brightness and originality. Cheap-looking fabrics, mostly artificial, feather boas, plastic or metal decorative elements instead of expensive jewellery, embroidery and prints as additional décor, simplicity, but at the same time, the conceptuality of the cut fully convey the ideas laid down by the creators of pop art, however this time in clothes.

\section{CONCLUSIONS}

Thus, the work comprehensively explores the artistic style of pop art and the means of graphic expression of one of the representatives of this style - Andy Warhol. Based on a detailed analysis of the source base, subject-visual material and scientific literature, the problems of research of the application of the semantic load of pop art in the context of modern costume design are clarified, it and its representatives are studied. Particular attention is paid to the study of the means of graphic expression of Andy Warhol. The social and cultural factors that influenced the artist were clarified, which allowed to better understand and systematize pop art as an art and creativity of the artist in the context of the problem of the influence of various factors on the creation of fashion trends on a social basis. As a result of the studied material a collection of men's and women's clothes, clothing with characteristic and inherent features of pop art culture were created. New, littleknown facts about the use of graphic means of expression as a way to influence society are revealed, the colour scheme and original texture are transferred. The analysis of modern fashion trends is carried out and, using the methods of systemstructural and morphological analysis, a grid with a large number of costume options for designing the collection is obtained.

\section{REFERENCES}

1. Uorkhol E., Khekett P. (2012) POPizm : Uorkholovskie 60-e [POPism: The Warhol 60s]. Moskva : Amfora. (in Russian).

2. Bodriyar Zh. (2006) Pop-art: iskusstvo obshchestva potrebleniya? [Pop Art: The Art of Consumer Society?] Bodriyar Zh. Obshchestvo 
potrebleniya. Yego mify i struktury [Baudrillard J. Consumer Society. Its myths and structures.]. Moskva : Kulturnaya revolyutsiya ; Respublika, pp. 150-158. (in Russian).

3. Buchkov V. V. (2003) Leksikon nonklassiki. Khudozhestvenno-esteticheskaya kultura XX veka [The lexicon of nonclassics. Artistic and aesthetic culture of the XX century]. Moskva : Drofa. (in Russian).

4. Chegodaev A. D. (1960) Iskusstvo Soedinennykh Shtatov Ameriki ot voyny za nezavisimost do nashikh dney [The art of United States from Revolurionary War to the present day]. Moskva : Iskusstvo. (in Russian)

5. Chuprina N., Kolosnichenko M. (2020). Eclecticism as the basis of design practices in the modern fashion system. Fashion design in a multicultural space : monograph. Kyjiv : KNUTD ; publisched by Academic Society of Michal Baludansky, Košice, Slovakia. Pp. 87-104.

6. Chuprina N., Krotova T., Pashkevich K., Kara-Vasylieva T., Kolosnichenko M. (2020). Formation of fashion system in the XX - the beginning of the XXI century. Vlakna a textile, no. 4 (28), pp. 48-57. http://vat.ft.tul.cz/2020/4/ VaT_2020_4_7.pdf (accessed 16 February 2021).

7. Encyklopedija dlja ditej. T. $7:$ Mystectvo. Ch. 2: Arkhitektura, obrazotvorche ta dekoratyvno-prykladne mystectvo 17-20 stolitj [Encyclopedia for children. Vol. 7 : Art, part 2 : Architecture, fine and decorative arts of 17-20 centuries.] Available at: http://bibliograph.com.ua/avanta/167.html (accessed 14 April 2021).

8. Khonnef K. (2005) Pop-art [Pop-art] / U. Grosenik (ed.). Moskva : Taschen ; Art-rodnik. (in Russian).

9. Kadochnikova K. M. (ed.) (2011) Slovar po iskusstvu [Dictionary of Art] Moskva : Drofa. (in Russian).

10. Kolosnichenko O., Baranova A., Prykhodko-Kononenko I. (2017). Design of concordant forms of modern clothes on the basis of proportional correlations of sacred geometry. Vlákna a textil, no. 3, pp. 10-14.

11. Kolosnichenko O., Ostapenko N., Kolosnichenko M. (2016). The development of new forms of special clothes by design projecting methods. Vlákna a textil, no. 2, pp. 3-8.

12. Kolpinskiy V. (ed.) (1980) Modernizm: Analiz i kritika osnovnykh napravleniy [Modernism: Analysis and critique of the main directions]. Moskva : Iskusstvo, 1980. (in Russian). 
Nataliia Chuprina, Olena Kolosnichenko. Pop art image and design characteristics...

13. Kozlovsjkyj P. (1996) Postmoderna kuljtura: suspiljno-kuljturni naslidky tekhnichnogho rozvytku [Postmodern culture: sjcio-cultural consequences of technical development]. Suchasna zarubizhna filosofija. Techiji i naprjamky [Modern foreign philosophy. Currents and directions.]. Kyjiv : Vakler, pp. 213-294. (in Ukrainian).

14. Kuzmina M. (1980) Pop-art [Pop-art]. Modernizm [Modernism]. Moskva. (in Russian).

15. Liu J., Krotova T., Yezhova O., Pashkevich K. (2018). Traditional Elements of Chinese Culture in Logo Design. International Circular of Graphic Education and Research, is. 11, pp. 66-75. Available at: https://www.internationalcircle.net/international_circle/international_circle/ international_circle/circular/issues/18_02/ICJ_11_2018_07 (accessed 20 June 2021).

16. Makovskiy S. (1999) Silueti amerikanskikh khudozhnikov [Silhuettes of American artists]. Moskva : Respublika. (in Russian).

17. Matvjejeva L. L. (2005) Kuljturologhija : konspekt lekcij [Culturology : lecture notes]. Kyjiv : Lybidj. (in Ukrainian).

18. Obukhova A., Orlova M. (2001) Zhivopis bez granits. Ot pop-arta k kontseptualizmu [Painting without borders. From pop-art to conceptualism]. Moskva : Galart. (in Russian).

19. Pashkevich K., Yezhova O., Kolosnichenko M., Ostapenko N., Kolosnichenko E. (2018). Designing of the complex forms of women's clothing, considering the former properties of the materials. Man-Made Textiles in India, vol. 46, is. 11, pp. 372-380.

20. Pop-art jak masove mystectvo [Pop-art as a Mass Art]. Available at: http:// megalib.com.ua/content/7929_Pop_art_yak_masove_mistectvo.html (accessed 23 December 2020). (in Ukrainian).

21. Pop-art style in modern youth clothing. Available at: http:// fashionstylist.kupivip.ru/article-27586-stil-pop-art-v-molodyozhnoy-sovremennoy-odezhde.html (accessed 28 January 2021). (in Russian).

22. Ctylj pop-art. [Pop-art style]. Available at: http://ukrslady.ru/moda-ta-stil/ modni-sekreti/59865-stil-pop-art.html (accessed 6 March 2021). (in Ukrainian).

23. Materialy konferentsii «Endi Uorkhol. Simpozium», 30-31 oktyabrya 2000 g. Sankt-Peterburg [Proceedings of the conference "Andy Warhol. Symposium", October 30-31, 2000. St. Pitersburg]. (in Russian). 
24. Rjaboshhuk K. V., Chuprina N. V., Shapoval A. Gh., Ghajova I. L. (2017) Moda jak socialjnyj projav pop-artu [Fashion as social display of pop-art]. Tekhnologhiji ta dyzajn, no. 1. Available at: http://nbuv.gov.ua/UJRN/td_2017_1_16 (accessed 8 Травень 2021). (in Ukrainian).

25. Trend lita - odjagh u styli pop-art [Summer trend - clothes in the style of pop-art]. Available at: http://lady.tochka.net/ua/64581-trend-leta-odezhdav-stile-pop-art/.html (accessed 8 Травень 2021). (in Ukrainian).

26. Iskusstvo pop-arta [The Pop-Art]. (2009) Art Library, no. 5, pp. 140-17. (in Russian).

27. Tolstoy A. (2001) Galaktika pop-arta [The Galaxy of pop art]. Novaya yunost, no. 4, pp. 11-14. (in Russian).

28. Vipper B. R. (1970) Stati ob iskusstve [Articles about art]. Moskva : Iskusstvo. (in Russian). 